\title{
Sound production during mating and disturbance in the West Indian sweet potato weevil, Euscepes postfasciatus (Fairmaire) (Coleoptera: Curculionidae)
}

\author{
Keiji Yasuda and Masaya Tokuzato ${ }^{1}$ \\ Okinawa Prefectural Agricultural Experiment Station, Naha, Okinawa 903-0814, Japan
}

(Received 23 February 1999; Accepted 21 July 1999)

\begin{abstract}
The production of courtship song, $87.9 \pm 8.5 \mathrm{~ms}$ in duration, by male Euscepes postfasciatus appears to be one step of the behavioral sequence leading to copulation. Females which had perceived the courtship song responded to this signal by remaining stationary and allowing males to mate, but unreceptive females or males produced disturbance songs, $22.5 \pm 1.9 \mathrm{~ms}$ or $16.9 \pm 2.2 \mathrm{~ms}$ in duration, respectively, and/or made jerky movements. When weevils were held with tweezers, they produced the disturbance song. This song may have a defense function.
\end{abstract}

Key words: West Indian sweet potato weevil (Euscepes postfasciatus), sound production, mating behavior

\section{INTRODUCTION}

The West Indian sweet potato weevil, $E \boldsymbol{E}$ scepes postfasciatus (Fairmaire), is known as an important insect pest of the sweet potato, Ipomoea batas L., in some countries of the South Pacific, the Caribbean Basin, and Central and South America (Sherman and Tamashiro, 1954; Raman and Alleyne, 1991). The first invasion of this species to Japan was recorded in Okinawa in 1947 (Asato, 1950). By 1954 the distribution had expanded over the entire Ryukyu Island chain (Takara, 1954), and it is currently causing severe damage in many sweet potato fields. Okinawa Prefecture started an E. postfasciatus eradication project in 1994, using a sterile insect release technique (Moriya, 1995). However, for the success of this project, information on the basic mating behavior is indispensible. Yasuda and Miyara (1992) found that both female and male adults of this weevil produced a sound by grating the abdomen on the elytron when they were disturbed, and called it a disturbance song. The song consisted of a repetition of a short sound unit. Other sounds were produced by adult weevils, but their structures and functions were not determined. Our observations suggested that one of these sounds was produced during mating. This was called a courtship song.

We confirm and describe the structure of these two different songs and determine their functions in relation to adult behaviors.

\section{MATERIALS AND METHODS}

Insects. Weevils originated from individuals collected from a wild population in a sweet potato field at Yomitan Village, Okinawa, Japan, in October 1994. They were maintained for three or four generations and reared with sweet potato tubers in the laboratory at $26 \pm$ $1^{\circ} \mathrm{C}, 14: 10 \mathrm{LD}$. Adults were sexed within $24 \mathrm{~h}$ of emergence as in Yasuda and Naito (1991), and female and male adults were kept individually in separate plastic cups $(5.5 \mathrm{~cm}$ dia., $3.5 \mathrm{~cm} \mathrm{ht}$.) with a piece of sweet potato tuber as food. To identify sex, male adults were marked on the forewing with a paint marker.

Relationship between courtship song and the mating behavior. To clarify the role of the courtship song in mating behaviors, three different kinds of pairs (male + female, male + male and female + female) were introduced into an acoustic box, and acoustical activities and mating behaviors were recorded.

Acoustical activities of weevils related to age.

${ }^{1}$ Present address: Kagamigaoka Handicapped School, Urasoe, Okinawa 901-2100, Japan 
To understand the relationship between the acoustical activities of the weevils and their age, 15 virgin females were observed for the production of disturbance and courtship songs during the 21 days after emergence at one or three-day intervals.

Recording and analysis. To record the courtship song, we used a transparent plastic tube (11 mm dia. $\times 50 \mathrm{~mm}$ length) (Fig. 1). One 10day-old male and one female weevil were introduced into a space at the middle of the tube into which a piece of sweet potato tuber was placed as food. The space was closed with nylon mesh so that the weevils could not interfere with the microphone. A tip of an electric condenser microphone (Bruel \& Kjar 4165) was inserted into the open end of the tube to within $3 \mathrm{~cm}$ from the mesh. An eyepiece microscope was inserted into the other open end to observe weevil behaviors. The tube was set into an acoustic box $(237 \times 285 \times 363 \mathrm{~mm})$ to eliminate external noise.

Headphones were used to monitor the sound of weevils during the experiment. Their behaviors were observed and courtship stridulations were recorded for $30 \mathrm{~min}$ for each pair. When insects first showed the behaviors near the end of the observation period, we continued recording the sound for more than $2 \mathrm{~h}$. We started observations from 1 to $3 \mathrm{~h}$ after lights-off.

In order to record the disturbance song, a one 10-day-old adult was introduced into a contain- er $(1.8 \times 1.8 \times 2.0 \mathrm{~m})$, and its body was pressed slightly by tweezers for $5 \mathrm{~s}$ at a distance of $2 \mathrm{~cm}$ from the microphone.

Sounds lower than $1 \mathrm{kHz}$ were considered as noise and eliminated by a high pass filter (Bruel \& Kjar). Sounds higher than $1 \mathrm{kHz}$ were amplified with a Bruel \& Kjar 2610 amplifier, and recorded with a Pioneer Electronics D-05 digital audio tape recorder. Song structures of courtship and disturbance songs were analyzed with a Bruel \& Kjar 2123 audio analyzer. Song structure was analyzed by an oscillograph and a sonagraph. The temporal measures (ms), the unit song interval (ms) and the maximum frequency $(\mathrm{Hz})$ were obtained with the audio analyzer.

\section{RESULTS}

In the experiment in which a pair of adults with different sex combinations were introduced in the tube, the courtship song was produced only by males while they were mounting either on a female or a male (Table 1). In the pairing of male and female, 31 of 82 males mounted females and 27 of these males produced the courtship song, suggesting that this song was associated with mating behavior. Of the females mounted by the 27 males, 22 females were inseminated successfully as determined by the presence of sperm in the receptaculum seminis. Nine females made the disturbance song when they were mounted or touched by the males. In

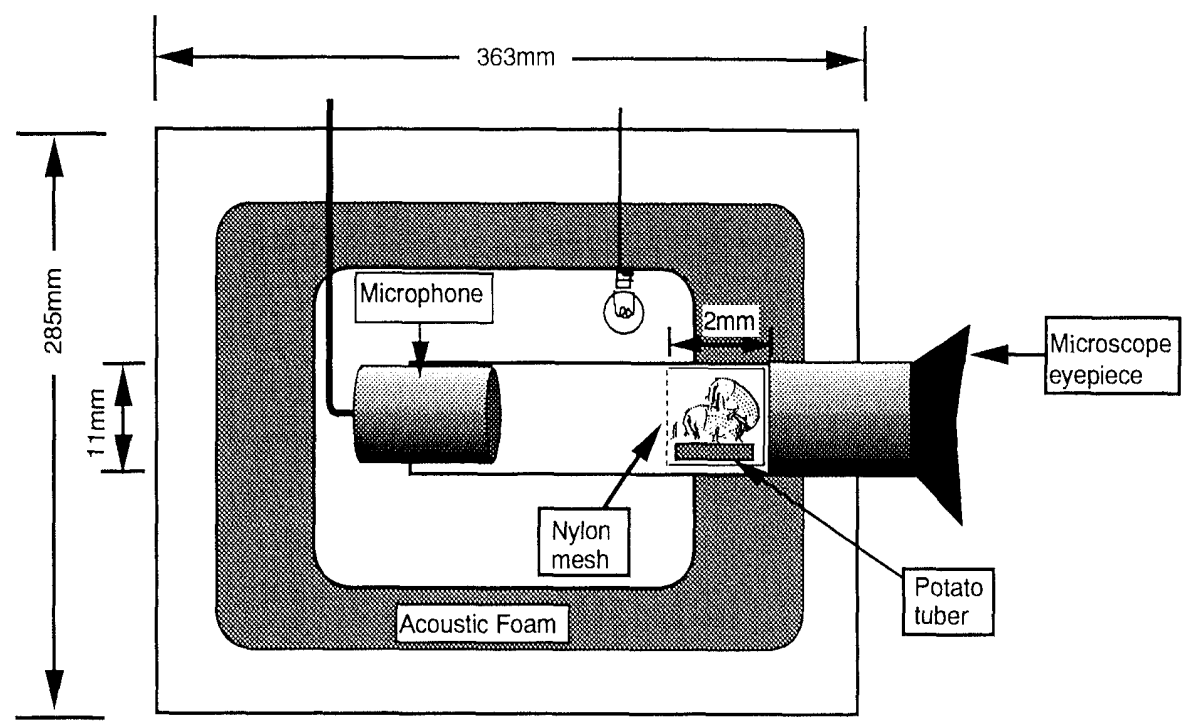

Fig. 1. Diagram of test chamber used to record stridulation and to observe behavior of $E$. postfasciatus. 
Table 1. Number of weevils producing courtship and disturbance songs under different combinations of both sexes

\begin{tabular}{|c|c|c|c|c|c|}
\hline \multirow{2}{*}{ Pairing } & \multirow{2}{*}{$\begin{array}{l}\text { Number of } \\
\text { pairs }\end{array}$} & \multicolumn{2}{|c|}{ Courtship song } & \multicolumn{2}{|c|}{ Disturbance song } \\
\hline & & $0^{1}$ & $q$ & $\sigma^{x}$ & $q$ \\
\hline Male and female & 82 & 27 & 0 & 0 & 9 \\
\hline Male and male & 16 & 5 & - & 2 & - \\
\hline Female and female & 15 & - & 0 & - & 0 \\
\hline
\end{tabular}

those cases only one male could copulate. Three pairs did not make sounds during mounting. In 5 of 16 male and male pairs, mounting males made the courtship song. Female female couples did not produce sounds throughout the

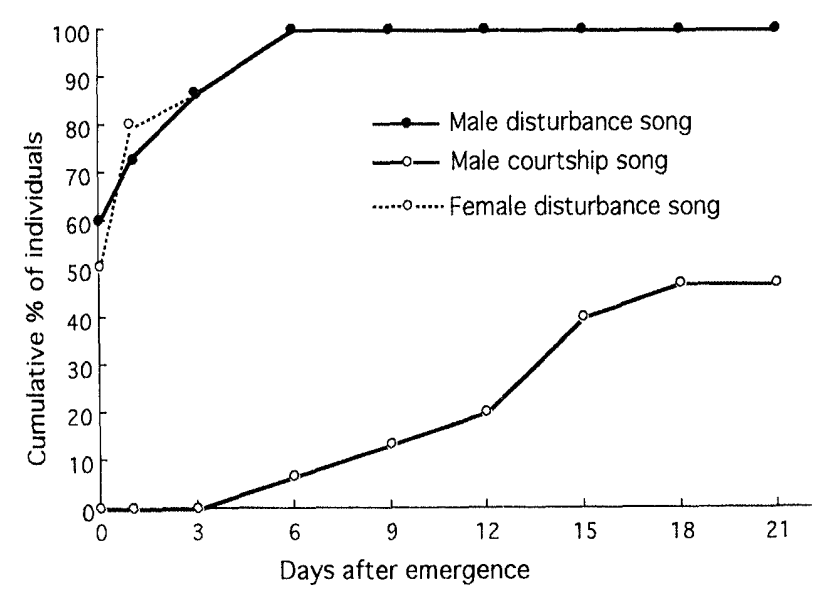

Fig. 2. Cumulative percentage of males producing courtship and disturbance songs and females producing disturbance song. observations. Two males produced disturbance songs when they were mounted by other males.

Both sexes produced the disturbance song from the day of adult emergence, and the song was continuously produced for at least 21 days after emergence (Fig. 2). Males began producing the courtship song on the 6th day after emergence when they attained sexual maturation (Kohama and Shimoji, 1998), and produced the song most frequently on the 15 th day after emergence. Typical examples of a sonograph and oscillograph of courtship and disturbance songs are shown in Figs. 3-5. The disturbance songs produced by males and females were similar (Figs. 4 and 5) and differed from the courtship songs produced by males (Fig. 3). That is, the courtship song consisted of a short pulse of $87.9 \mathrm{~ms}$ that was repeated several times during the courtship at intervals of $2,466.3 \mathrm{~ms}$ (Table 2). On the other hand, the disturbance song in females and males consisted of short

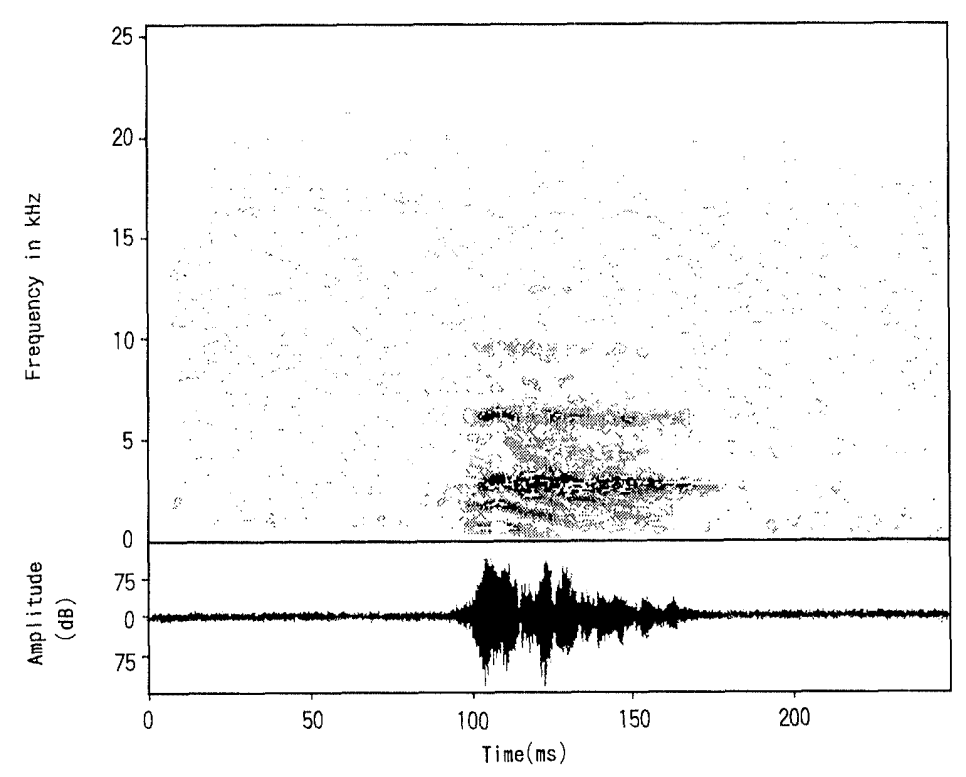

Fig. 3. Sonograph (top) and oscillograph (bottom) of the courtship song of E. postfasciatus males. 


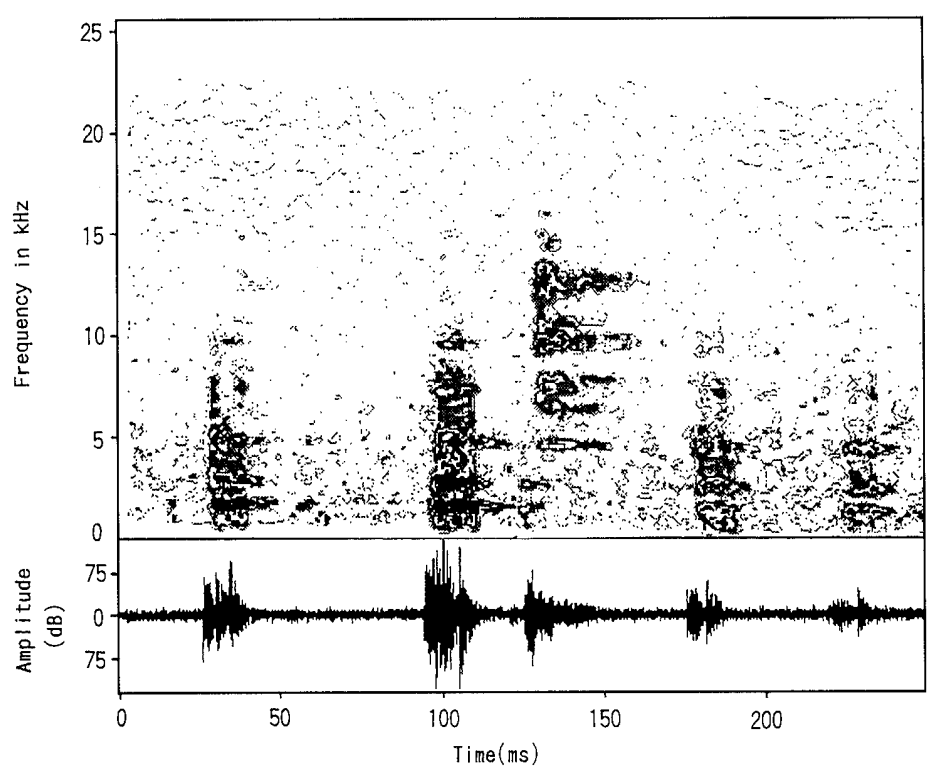

Fig. 4. Sonograph (top) and oscillograph (bottom) of the disturbance song of $E$. postfasciatus males.

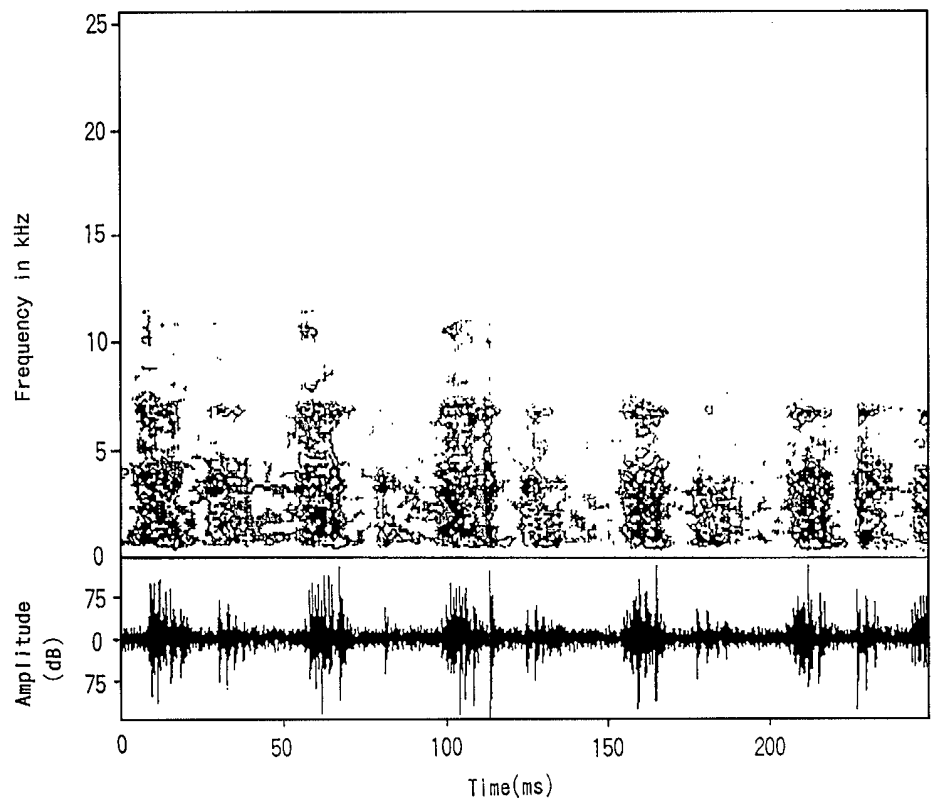

Fig. 5. Sonograph (top) and oscillograph (bottom) of the disturbance song of $E$. postfasciatus females.

Table 2. Principal characteristics of the courtship and disturbance songs of E. postfasciatus

\begin{tabular}{|c|c|c|c|c|c|}
\hline Song type & Sex & $n$ & $\begin{array}{l}\text { Duration of song } \\
(\mathrm{ms})^{\mathrm{a}}\end{array}$ & $\begin{array}{l}\text { Inter-song interval } \\
\qquad(\mathrm{ms})^{\mathrm{a}}\end{array}$ & $\begin{array}{c}\text { Maximum } \\
\text { frequency }(\mathrm{Hz})^{\mathrm{a}}\end{array}$ \\
\hline Disturbance & Female & 9 & $22.5 \pm 1.9 \mathrm{a}$ & $23.0 \pm 7.1 \mathrm{a}$ & $3,580 \pm 2,490$ \\
\hline Disturbance & Male & 5 & $16.9 \pm 2.2 \mathrm{a}$ & $24.4 \pm 4.5 \mathrm{a}$ & $2,860 \pm 1,250$ \\
\hline Courtship & Male & 9 & $87.9 \pm 8.5 b$ & $2,466.3 \pm 911.4 b$ & $3,880 \pm 1,930$ \\
\hline
\end{tabular}

\footnotetext{
${ }^{a}$ Values are mean \pm SE. Means followed by different letters are significant by Scheffé's test $(p<0.01)$.
} 
pulses of 22.5 and $16.9 \mathrm{~ms}$ with inter-song intervals of 23.0 and $24.4 \mathrm{~ms}$, respectively. There was no significant difference in the disturbance songs produced by females and males in the duration of a song or inter-song interval (Table 2). In contrast, there was a significant difference between disturbance song and courtship song in temporal measures or the intersong interval (Scheffé's test, $p<0.01$, in both cases), but no difference in the maximum frequency Scheffé's test, $p=0.680$ ).

\section{DISCUSSION}

Alexander (1967) distinguished the acoustical communication in arthropods into several functional categories of acoustical output. According to him, disturbance stridulation is a sound produced by either sex in response to intraspecific or interspecific communication. Its function is primarily for defense or communication. Courtship stridulation is an intraspecific sound produced usually by males after pair-forming, and terminates with insemination. Wilson et al. (1993) could not observe any difference in the sound producing structure in male and female Pyrydiuchus tau, but only males stridulated during courtship. Similarly, the structures of elytra and abdomen of $E$. postfasciatus which associate with sound production were also similar in both sexes (Yasuda and Miyara, 1992).

The production of courtship song by male $E$. postfasciatus appears to be one step of the behavioral sequence leading to copulation. Females which had perceived the courtship song responded to this signal by remaining stationary and allowing males to mate, but unreceptive females produced disturbance songs and/or made jerky movements. When weevils were held by tweezers, they produced the disturbance song. This song may have a defense function; it may startle a predator and give weevils an op- portunity to fall down to the ground and escape (Yasuda and Miyara, 1992).

Future studies are needed to experimentally test whether the courtship song is a prerequisite to copulation, and whether the disturbance song is effective against predators.

\section{ACKNOWLEDGEMENTS}

We thank Dr. K. Nakamura, Okinawa University, Dr. N. Arakaki and Dr. T. Miyatake, Okinawa Prefectural Agricultural Experiment Station, and Dr. T. Shimizu, National Institute of Sericulture and Entomological Science, for their valuable suggestions and critical readings of the manuscript.

\section{REFERENCES}

Alexander, R. D. (1967) Acoustical communication in arthropods. Annu. Rev. Entomol. 12: 495-526.

Asato, S. (1950) West Indian sweet potato weevil as new sweet potato pest. Kunigami Noho 2(8): 5-11 (in Japanese).

Kohama, T. and Y. Shimoji (1998) Reproductive maturity of female West Indian sweet potato weevil, Euscepes postfasciatus (Fairmaire) (Coleoptera: Curculionidae). Appl. Entomol. Zool. 33: 1-4.

Moriya, S. (1995) The possibility of eradicating two sweet potato pests, Cylas formicarius and Euscepes postfasciatus, in Japan. FFTC Exten. Bull. 403: 1-7.

Raman, K. V. and E. H. Alleyne (1991) Biology and management of the West Indian sweet potato weevil, Euscepes postfasciatus. In Sweet Potato Pest Management: A Global Perspective (R. K. Jansson and K. V. Raman eds.). Westview Press, Boulder, Colorado, pp. 263-281.

Sherman, M. and M. Tamashiro (1954) The sweet potato weevils in Hawaii; their biology and control. Hawaii Agric. Exp. Stn. Tech. Bull. 23: 1-36.

Takara, T. (1954) Dissemination and control of vine borer of sweet potato and West Indian sweet potato weevil. Shokubutsu-bôeki 8: 18-20 (in Japanese).

Wilson, L. M., C.S. Henry, J. B. Johnson and J. P. McCaffrey (1993) Sound production in Phrydiuchus tau (Coleoptera: Curculionidae). Ann. Entomol. Soc. Am. 86: 621-630.

Yasuda, K. and A. Miyara (1992) Sound production of the West Indian sweet potato weevil, Euscepes postfasciatus (Fairmaire) (Coleoptera: Curculionidae). Proc. Assoc. Pl. Prot. Kyushu 38: 89-91 (in Japanese).

Yasuda, K. and T. Naito (1991) External characters for discriminating sex in the West Indian sweet potato weevil, $E \mathbf{u}$ scepes postfasciatus (Fairmaire) (Coleoptera: Curculionidae). Appl. Entomol. Zool. 26: 422-424. 